\title{
Factors Associated with Intention to Utilize Cervical Cancer Prevention Strategies among Pregnant Women Attending Antenatal Clinics in Ibadan, Nigeria
}

\author{
O. B. Ani, C. O. Aimakhu, I. O. Morhason-Bello
}

\section{ABSTRACT}

Cervical cancer is the second commonest cancer among women in Nigeria, with one-third of all cases occurring during the reproductive period. However, different barriers, including the unaffordability of vaccines and ineffective screening programs, delay preventive measures. Hence, the need to adequately tackle those barriers to improve uptake. Using an interviewer-administered questionnaire, the descriptive cross-sectional study design was adopted to gather data from 344 pregnant women attending antenatal clinics in three hospitals in Ibadan. Data collected were entered into the Statistical Package for Social Sciences, version 20.0. Frequency distribution tables, mean, figures, and multinomial logistics regression were used to summarize and present the data. Most Pregnant women, $34.3 \%$, were aged between $25-29$ years, with 35.8 . $\%$ of them having poor knowledge of HPV, while $61.1 \%$ had poor knowledge of cervical cancer. Also, $43.3 \%$ of the participants had never heard of HPV. In addition, $\mathbf{4 7 . 7 \%}$ of respondents stated that distance to a health facility could hinder their utilization of cervical cancer prevention strategies. The multinomial logistic regression showed a significant association between awareness of HPV Vaccination and plan for HPV vaccination aOR 0.32 CI (0.14 - 0.76), and plan for cervical cancer screening aOR 0.24 CI (0.11 0.53) respectively. It is crucial to correct the negative perception and attitude towards cervical cancer and its preventive measures to help to increase its adoption.

Keywords: Cervical cancer, factors, intention, preventive measures.
Submitted: January 16, 2022

Published: February 10, 2022

ISSN: 2593-8339

DOI: $10.24018 /$ ejmed.2022.4.1.1210

O. B. Ani*

Department of Reproductive Health Sciences, Pan African University, Nigeria.

(e-mail: aniodinaka@gmail.com) C. O. Aimakhu

Department of Obstetrics and Gynaecology, University of Ibadan, Nigeria.

(e-mail: aaimakhuchris@yahoo.com)

I. O. Morhason-Bello

Department of Obstetrics and Gynaecology, University of Ibadan, Nigeria. (e-mail:

imranmorhasonbello@gmail.com)

*Corresponding Author

\section{INTRODUCTION}

Cervical cancer burden remains high worldwide with an estimated 578,000 cases and 266,000 deaths each year, and it is both the fourth most common cause of cancer and the fourth most common cause of death from cancer in women [1], [2]. These death rates have continued to increase annually, with an estimated 570,000 cases and 311,000 deaths in 2018, which rose to 604,127 cases and 341,831 deaths in 2020 [3]. In Nigeria, GLOBOCAN, 2020, estimates that cervical cancer is the second commonest cancer among women in Nigeria, with an Age Standardized Incidence Rate (ASR) of 18.4 per 100,000 . Hence, indicating the need for improved cervical cancer prevention strategies from young ages.

The Human Papillomavirus (HPV) infection, responsible for $90 \%$ of cervical cancer cases, has a disproportionately high burden in low-and-middle-income countries, with more than $90 \%$ of the estimated 3110,000 deaths from the disease occurring in these countries [4]-[6]. Cervical cancer is responsible for around $12 \%$ of all cancer cases and $7.5 \%$ of all cancer-related deaths in developing countries [7]. These marked differences can be explained by inadequate access to screening services that facilitate early detection and treatment, low preventive health behavior, and lack of access to effective screening services [8], [9]. It has also been noted that one-third of all cervical carcinomas occur during the reproductive period with $3 \%$ of cervical cancer cases being diagnosed during pregnancy [10], [11]. The risk of HPV infection is higher during pregnancy owing to hormonal changes and immunosuppression [12].

The high cervical cancer mortality in low-and-middleincome countries is also majorly attributed to the unaffordability of vaccines, ineffective screening programs, limited access to cervical cancer screening, and low levels of follow-up treatment after abnormal test results preventive methods of cervical cancer [13]. Cervical cancer screening using cytology (Papanicolaou test) has been a highly successful public health intervention for the early detection of precancerous lesions in the cervix [14]. However, this breakthrough is limited in availability and accessibility.

The barriers to cervical cancer screening services underutilization include personal barriers like lack of knowledge about the importance of screening, misconceptions, and negative health beliefs [15], [16], community and health system structural barriers such as lack of community support [17], and inaccessibility of the 
screening services [18], [19]. HPV vaccines exist, and it is recommended for children between the ages of 9 and 12 [6]. Unfortunately, the HPV vaccination is not included in the routine vaccination programs, and this serves as a hindrance in the control of the virus spread. Therefore, the principal aim of the study was to identify the perception, attitude, and factors influencing the intention to utilize cervical cancer preventive measures among pregnant women in Ibadan.

\section{Materials AND Methods}

\section{A. Study Design, Setting and Population}

A quantitative cross-sectional study was conducted among pregnant women attending antenatal clinics in University College Hospital, Adeoyo Maternity Teaching Hospital, and the Agbowo Primary Healthcare Centre. These hospitals were chosen because they offer maternal and child health services to many women in the state. Data collection spanned a total of seven weeks, and a total of 344 respondents were interviewed. All pregnant women who attended ANC at the selected facilities and those who gave informed consent met the inclusion criteria, while all pregnant women who were psychologically unstable or ill at the time of data collection and those that refused to give consent were excluded.

\section{B. Instrument for Data Collection}

An interviewer-administered questionnaire made up of five sections was used for data collection. Section A collected information about respondents' socio-demographic data. Section B acquired information about knowledge and perception towards cervical cancer prevention. Section $C$ was on attitude towards cervical cancer prevention strategies. Section D was on concerns about the utilization of cervical cancer prevention strategies, while section E collected information about factors influencing intention to utilize cervical cancer prevention strategies. The project supervisors assessed the face and content validity, while the construct validity was assessed by other experts in Obstetrics, Gynaecology, and oncology. The reliability was determined using the split-half method, where the instrument was administered to pregnant women in a facility different from the selected ones by dividing them into odd and even numbers, after which a reliability coefficient of greater than 0.8 determined the instrument strongly reliable.

\section{Sampling and Data Collection}

The selection of participants was made using the multistage sampling method. At Stage I, the convenience sampling method selected the primary, secondary, and tertiary health care facilities. At Stage II, the proportionate sampling method was used to select women in each facility, while the systematic random sampling method was used to select every 3rd ANC attendee. A letter of introduction was obtained from the department, and the proposal was submitted to the $\mathrm{UI} / \mathrm{UCH}$ ethical review board and Oyo state Ministry of health to obtain ethical clearance for the study. Two research assistants were trained on data collection processes for one day. They simulated the data collection process, after which they assisted in administering the questionnaires to the respondents. Permission was taken from the clinic head at the first meeting, and subsequently, at each meeting, the respondents were met on a one-on-one basis with the study's purpose explained, after which an informed consent form was given to them to complete. Respondents filled out the questionnaires at the different settings selected for the study, and it was retrieved immediately after. Ethical principles of confidentiality, beneficence, non-maleficence, and justice were upheld throughout the study.

\section{Method of Data Analysis}

The quantitative data were entered, cleaned, and analyzed using SPSS version 20.0. Descriptive summaries, frequency tables, and graphs were used to describe the data. For the statistical tests, P-value $\leq 0.05$ was considered as statistical significance. A multinomial regression including a crude and adjusted odds ratio and confidence interval was constructed to determine the extent to which dependent and independent variables were associated.

\section{E. Ethics Consideration}

Ethics approval for this study was obtained from the UI/UCH ethical review board, The Oyo state ethical committee with ethical approval number- AD 13/479/4099B, and the Ibadan North Local Government. The purpose of the study, assurance of confidentiality and anonymity of respondents' information, was included in the consent form and explained verbally to the participants.

\section{RESULTS}

Results from the study show that the greatest proportion of women $(34.3 \%)$ were aged between $25-29$ years, and $76.4 \%$ were majorly Yoruba. More so, the greatest proportion, $67.7 \%$, had tertiary education as the highest level of education, while $79.7 \%$ earned less than or equal to 50,000 naira. Also, $68.2 \%$ of them were multiparous (Table I).

Results from Table II portray that $35.8 \%$ of the respondents had poor knowledge of HPV, while the greatest proportion, $61.1 \%$, had poor knowledge of cervical cancer.

Results from the study, as stated in Table III, shows that $83.3 \%$ of the women do not think cervical cancer is preventable, with $63.1 \%$ of them disagreeing with being faithful to partner as a method of primary prevention of cervical cancer, while $57.4 \%$ also disagreed with pap smear being a secondary means of prevention.

Results from the study in Table IV portray that a proportion of the women are contemplating utilizing cervical cancer preventive measures, as $45.6 \%$ stated they might be willing to encourage their family members to take HPV Vaccination, with $41.9 \%$ and $41.3 \%$ respectively, stating that they may be willing to pay for HPV Vaccination and take HPV vaccination, which are all primary prevention methods. More so, $45.9 \%$ stated they would encourage their family members to receive a pap smear, while $45.9 \%$ stated they might be willing to pay for a pap smear, with $52.9 \%$ stating they plan to do a cervical cancer screening.

The most significant concerns about HPV Vaccination were abnormal vaginal bleeding and persistent pelvic pain as identified by $47.8 \%$ and $46.7 \%$ of the participants, with $34.3 \%$ having concerns about all the issues raised. Also, $80.2 \%$ of the respondents stated they had not had a pap smear before (Table V). 
TABLE I: SOCIO-DEMOGRAPHIC AND OBSTETRIC CHARACTERISTICS OF PREGNANT WOMEN IN IBADAN

\begin{tabular}{|c|c|c|}
\hline & $\begin{array}{c}\text { Frequency } \\
\mathrm{N}=344 \\
\end{array}$ & Percentage \\
\hline \multicolumn{3}{|c|}{$\begin{array}{ll}\text { Age }(30 \pm 8) * \\
\end{array}$} \\
\hline $18-24$ years & 36 & 10.5 \\
\hline $25-29$ years & 118 & 34.3 \\
\hline $30-34$ years & 98 & 28.5 \\
\hline $35-39$ years & 57 & 16.6 \\
\hline $40-57$ years & 35 & 10.2 \\
\hline \multicolumn{3}{|c|}{ Marital Status ${ }^{1}$} \\
\hline Not living with partner & 443 & 12.8 \\
\hline Living with partner & 294 & 87.2 \\
\hline \multicolumn{3}{|c|}{$\begin{array}{l}\text { Ethnicity }^{2} \\
\end{array}$} \\
\hline Yoruba & 259 & 76.4 \\
\hline Others & 80 & 23.6 \\
\hline \multicolumn{3}{|c|}{ Religion } \\
\hline Christianity & 200 & 58.1 \\
\hline Islam & 144 & 41.9 \\
\hline \multicolumn{3}{|c|}{ Education $^{3}$} \\
\hline Primary or none & 29 & 8.8 \\
\hline Secondary education & 78 & 23.6 \\
\hline Tertiary education & 224 & 67.7 \\
\hline \multicolumn{3}{|c|}{ Income $^{4}$} \\
\hline "Less than 50,000naira & 67 & 20.3 \\
\hline$\geq 50,000$ naira & 263 & 79.7 \\
\hline \multicolumn{3}{|c|}{ Parity ${ }^{5}$} \\
\hline Nulliparous & 6 & 2.0 \\
\hline Primiparous & 90 & 29.7 \\
\hline Multiparous & 193 & 68.2 \\
\hline
\end{tabular}

TABLE IV: CONCERN ABOUT HPV VACCINATION

\begin{tabular}{ccc}
\hline \hline Concerns about HPV vaccination & \\
\hline Persistent pelvic pain $^{1}$ & 136 & 46.7 \\
Abnormal vaginal bleeding $^{2}$ & 107 & 47.8 \\
Abnormal vaginal discharge $^{3}$ & 95 & 35.5 \\
Pain during sex ${ }^{4}$ & 91 & 36.8 \\
No concern $^{\text {Any of the 4 concerns }}$ & 62 & 18.0 \\
Concerned about all & 282 & 82.0 \\
Has anyone had a pap smear in your family & \\
No & 276 & 80.2 \\
Yes & 68 & 19.8 \\
Who has had a pap smear? & 50 & 14.5 \\
Myself & 45 & 13.1 \\
Daughter & 39 & 11.3 \\
Other &
\end{tabular}

Results from the study in Table IV portray that a proportion of the women are contemplating utilizing cervical cancer preventive measures, as $45.6 \%$ stated they might be willing to encourage their family members to take HPV Vaccination, with $41.9 \%$ and $41.3 \%$ respectively, stating that they may be willing to pay for HPV Vaccination and take HPV vaccination, which are all primary prevention methods. More so, $45.9 \%$ stated they would encourage their family members to receive a pap smear, while $45.9 \%$ stated they might be willing to pay for a pap smear, with $52.9 \%$ stating they plan to do a cervical cancer screening.

The most significant concerns about HPV Vaccination were abnormal vaginal bleeding and persistent pelvic pain as identified by $47.8 \%$ and $46.7 \%$ of the participants, with $34.3 \%$ having concerns about all the issues raised. Also, $80.2 \%$ of the respondents stated they had not had a pap smear before (Table V).

\begin{tabular}{|c|c|c|}
\hline & $\begin{array}{c}\text { Frequency } \\
\mathrm{N}=344\end{array}$ & Percentage \\
\hline \multicolumn{3}{|c|}{ Knowledge of HPV } \\
\hline Poor Knowledge & 123 & 35.8 \\
\hline Fair Knowledge & 206 & 59.9 \\
\hline Good Knowledge & 15 & 4.4 \\
\hline \multicolumn{3}{|c|}{$\begin{array}{l}\text { Knowledge of Cervical Cancer } \\
\end{array}$} \\
\hline Poor Knowledge & 210 & 61.1 \\
\hline Fair Knowledge & 107 & 31.1 \\
\hline Good Knowledge & 27 & 7.9 \\
\hline
\end{tabular}

TABLE III: AWARENESS OF CERVICAL CANCER PREVENTION STRATEGIES

\begin{tabular}{ccc}
\hline \hline & \multicolumn{2}{c}{$\begin{array}{c}\text { Frequency (Percent) } \\
\mathrm{N}=344\end{array}$} \\
\cline { 2 - 3 } & Yes & No \\
\hline \hline Is Cervical Cancer preventable? & $48(16.7)$ & $240(83.3)$ \\
\hline \hline Primary Prevention Methods \\
\hline \hline Sexual abstinence & $185(53.8)$ & $159(46.2)$ \\
Being faithful to partner & $127(36.9)$ & $217(63.1)$ \\
Using condom & $165(48.0)$ & $179(52.0)$ \\
Vaccination & $172(50.0)$ & $172(50.0)$ \\
Others & $271(78.8)$ & $73(21.2)$ \\
\hline \hline Secondary Prevention Methods \\
\hline \hline HPV test or screening & $153(48.6)$ & $162(51.4)$ \\
Pap smear test or VIA & $101(42.6)$ & $136(57.4)$ \\
Other preventive measures & $200(58.1)$ & $144(41.9)$ \\
\hline \hline
\end{tabular}

Results from the study show that the most mentioned factor was the distance to a health facility as identified by $47.7 \%$ of participants, followed by the cost of screening, $34.6 \%$, husband's permission, $28.2 \%$, and unexposure to causative factors, $24.7 \%$. (Table VI).

The multinomial logistics regression in Table VII is the regression output of factors associated with the plan to take HPV vaccination among participants. The odds of not planning to get HPV vaccination was significantly higher among participants who were aware of HPV vaccination (aOR: 9.29; 95\% CI: 1.68 - 51.23), while the odds of not planning for HPV vaccination was lower among participant who were aware of cervical cancer prevention strategies (aOR: 0.08; 95\% CI: $0.01-0.64$ ). After adjusting for other variables, religion remained significantly associated with participants' plans to take HPV vaccination; Muslims were more likely to plan for HPV vaccination than their Christian counterparts (Adjusted OR (aOR):3.67; 95\% CI: 1.54 - 8.74).

On the other hand, a participant who earned 50,000 Naira and above as monthly income, those who were aware of HPV vaccination, had concerns about HPV vaccination and were aware of HPV test and screening had a lower odd to be indecisive about HPV vaccination (aOR: 0.37; 0.32; 0.36; 0.16 and $95 \%$ CI: $0.17-0.82 ; 0.14-0.76 ; 0.14-0.90 ; 0.07-$ 0.35 respectively). Also, participants who had a family history of pap smear test were more likely to be indecisive about their plan (aOR: 3.41; 95\% CI: $1.01-11.56$ ), and those who believed that cervical cancer is associated with infection had lower odds to be indecisive than those who do not believe that cervical cancer is associated with infection (aOR: 0.15; 95\% CI: $0.004-0.53$ ). 
TABLE IV: INTENTION OF WOMEN TO UTILIZE CERVICAL CANCER PREVENTION STRATEGIES

\begin{tabular}{|c|c|c|c|c|}
\hline & & \multicolumn{3}{|c|}{ Frequency (Percent) $\mathrm{N}=344$} \\
\hline & & Yes & No & Maybe \\
\hline \multirow[t]{3}{*}{ Primary } & Plan to take HPV vaccination & $132(38.4)$ & $70(20.3)$ & $142(41.3)$ \\
\hline & Willingness to pay for HPV vaccination & $143(41.6)$ & $57(16.6)$ & $144(41.9)$ \\
\hline & Encourage family members to take HPV vaccination & $136(39.5)$ & $51(14.8)$ & $157(45.6)$ \\
\hline \multirow[t]{3}{*}{ Secondary } & Plan Cervical cancer screening & $182(52.9)$ & $60(17.4)$ & $102(29.7)$ \\
\hline & Willingness to pay for pap smear & $148(43.0)$ & $38(11.1)$ & $158(45.9)$ \\
\hline & Encourage family member to receive pap smear & $158(45.9)$ & $68(19.8)$ & $118(34.3)$ \\
\hline
\end{tabular}

TABLE V: BARRIERS TO UTILIZATION OF SECONDARY CERVICAL CANCER SCREENING OR PREVENTION STRATEGIES

\begin{tabular}{ccc}
\hline & \multicolumn{2}{c}{ Frequency (Percent) } \\
& Yes & No \\
\hline \hline Distance to a health facility & $164(47.7)$ & $180(52.3)$ \\
Cost of screening & $119(34.6)$ & $225(65.4)$ \\
Husband disagrees & $97(28.2)$ & $247(71.8)$ \\
Religion & $65(18.9)$ & $279(81.1)$ \\
Cultural values & $79(23.0)$ & $265(77.0)$ \\
Un-exposure to causative factors & $85(24.7)$ & $259(75.3)$ \\
Health worker's attitude & $62(18.0)$ & $282(82.0)$ \\
Fear of the result & $71(20.6)$ & $272(79.4)$ \\
\hline \hline
\end{tabular}

TABLE VI: MULTINOMIAL REGRESSION OF PLAN FOR HPV VACCINATION

\begin{tabular}{|c|c|c|c|c|}
\hline & \multicolumn{2}{|c|}{ CRUDE OR $(95 \% \mathrm{CI})$} & \multicolumn{2}{|c|}{ Adjusted OR } \\
\hline & No plan & Undecided & No plan & Undecided \\
\hline \multicolumn{5}{|c|}{ LEVEL 1 (Socio-demographic) } \\
\hline Age & \multicolumn{2}{|c|}{$\mathrm{p}=0.833$} & \multicolumn{2}{|c|}{$\mathrm{p}=0.498$} \\
\hline (In years) & $0.98(0.93-1.04)$ & $1.00(0.96-1.04)$ & $1.04(0.94-1.16)$ & $1.04(0.97-1.11)$ \\
\hline Marital Status & \multicolumn{2}{|c|}{$\mathrm{p}=0.537$} & \multicolumn{2}{|c|}{$\mathrm{p}=0.963$} \\
\hline Single & 1 & 1 & 1 & 1 \\
\hline Married & $1.20(0.42-3.44)$ & $1.52(0.73-3.17)$ & $0.86(0.21-3.58)$ & $0.90(0.36-2.22)$ \\
\hline Ethnicity & \multicolumn{2}{|c|}{$\mathrm{p}=0.169$} & \multicolumn{2}{|c|}{$\mathrm{p}=0.123$} \\
\hline Yoruba & 1 & 1 & 1 & 1 \\
\hline Others & $0.46(0.18-1.18)$ & $0.69(0.39-1.21)$ & $0.36(0.11-1.20)$ & $0.61(0.31-1.18)$ \\
\hline Religion & \multicolumn{2}{|c|}{$\mathrm{p}=0.014$} & \multicolumn{2}{|c|}{$\mathrm{p}=0.010$} \\
\hline Christianity & 1 & 1 & 1 & 1 \\
\hline Islam & $2.89(1.40-5.95)$ & $1.28(0.78-2.08)$ & $3.67(1.54-8.74)$ & $1.55(0.87-2.77)$ \\
\hline Education & \multicolumn{2}{|c|}{$\mathrm{p}=0.003$} & \multicolumn{2}{|c|}{$\mathrm{p}=0.025$} \\
\hline Primary or none & 1 & 1 & 1 & 1 \\
\hline Secondary education & - & $1.57(0.63-3.91)$ & - & $1.79(0.62-5.20)$ \\
\hline Tertiary education & - & $0.76(0.34-1.68)$ & - & $1.31(0.45-3.80)$ \\
\hline Income & \multicolumn{2}{|c|}{$\mathrm{p}<0.001$} & \multicolumn{2}{|c|}{$\mathrm{p}=0.002$} \\
\hline Less than 50,000naira & 1 & 1 & 1 & 1 \\
\hline$\geq 50,000$ naira & $0.98(0.34-2.86)$ & $0.32(0.17-0.60)$ & $2.60(0.58-11.70)$ & $0.37(0.17-0.82)$ \\
\hline Parity & & 275 & & \\
\hline Number of living children & $0.92(0.66-1.27)$ & $0.84(0.68-1.04)$ & $0.99(0.69-1.41)$ & $0.93(0.73-1.18)$ \\
\hline \multicolumn{5}{|c|}{ LEVEL 2 (Primary) } \\
\hline "Awareness of HPV vaccination & \multicolumn{2}{|c|}{$\mathrm{p}<0.001$} & \multicolumn{2}{|c|}{$\mathrm{p}<<0.001$} \\
\hline No & 1 & 1 & 1 & 1 \\
\hline Yes & $0.84(0.38-1.88)$ & $0.15(0.09-0.27)$ & $9.29(1.68-51.23)$ & $0.32(0.14-0.76)$ \\
\hline Family history of HPV vaccination & \multicolumn{2}{|c|}{$\mathrm{p}<0.001$} & \multicolumn{2}{|c|}{$\mathrm{p}<0.001$} \\
\hline No & 1 & 1 & 1 & 1 \\
\hline Yes & \multirow{2}{*}{\multicolumn{2}{|c|}{$p=0.16(0.08-0.32)$}} & - & $0.40(0.14-1.08)$ \\
\hline Concerns about HPV vaccination & & & \multicolumn{2}{|c|}{$\mathrm{p}=0.061$} \\
\hline No & 1 & 1 & 1 & 1 \\
\hline Yes & $0.36(0.14-0.92)$ & $0.32(0.16-0.64)$ & $0.38(0.11-1.24)$ & $0.36(0.14-0.90)$ \\
\hline Awareness of HPV test and screening & & 001 & & \\
\hline No & 1 & 1 & 1 & 1 \\
\hline Yes & $0.22(0.10-0.48)$ & $0.08(0.04-0.14)$ & $0.39(0.12-1.24)$ & $0.16(0.07-0.35)$ \\
\hline & LEVEL 3 (Seconc & & & \\
\hline A Awareness of cervical cancer & $\mathrm{p}=$ & 06 & & \\
\hline No & 1 & 1 & 1 & 1 \\
\hline Yes & $0.30(0.11-0.83)$ & $0.36(0.18-0.72)$ & $0.43(0.03-5.51)$ & $1.09(0.30-3.95)$ \\
\hline Awareness of cervical cancer prevention strategies & $\mathrm{p}=$ & 90 & & \\
\hline No & 1 & 1 & 1 & 1 \\
\hline Yes & $0.32(0.12-0.87)$ & $0.86(0.40-1.85)$ & $0.08(0.01-0.64)$ & $2.03(0.63-6.55)$ \\
\hline Family history of pap smear test & & 05 & & \\
\hline No & 1 & 1 & 1 & 1 \\
\hline Yes & $0.55(0.22-1.35)$ & $0.36(0.19-0.68)$ & $3.69(0.50-27.30)$ & $3.41(1.01-11.56)$ \\
\hline & LEVEL 4 (Dist & & & \\
\hline Belief that cervical cancer is associated with infection & & 01 & & \\
\hline No & 1 & 1 & 1 & 1 \\
\hline Yes & $0.37(0.14-1.00)$ & $0.17(0.09-0.34)$ & $0.26(0.03-2.02)$ & $0.15(0.04-0.53)$ \\
\hline
\end{tabular}

Multinomial logistic regression analyses were performed to identify the key sociodemographic, primary, secondary and distal factors associated with saying no and being undecided about utilizing cervical cancer preventive measures. All predictors are adjusted for all other covariates in the model. Note: aOR adjusted odds ratios, $95 \%$ CIs $95 \%$ confidence intervals for the adjusted odds ratios are highlighted in bold. 
Table VIII displays the results of the multinomial regression of the plan for cervical cancer screening among participants. In the adjusted model, a weak association existed between age and plan for cervical cancer screening. A unit increase in the participant's age increased the likelihood of being undecided in their plan for cervical cancer screening (aOR: 1.06; 95\% CI: $1.00-1.13$ ). A participant who had primary or no formal education have a higher odd of being undecided in their plan for cervical cancer screening. In contrast, a participant who earned 50,000 naira and above had a lower odd of being undecided in their plan for cervical cancer screening (aOR: $0.40 ; 95 \%$ CI: $0.18-0.86$ ), and as the number of living children increases, the odds of being undecided about cervical cancer screening test dropped.

The odds of being undecided about cervical cancer screening was lower among participants who were aware of HPV vaccination, those that had a family history of HPV vaccination, and those that reported a family history of pap smear test (aOR: $0.24 ; 0.11 ; 0.08$ and $95 \% \mathrm{CI}=0.11-0.53$; $0.02-0.51$ and $0.01-0.69)$.

TABLE VII: MULTINOMIAL REGRESSION ON WILLINGNESS TO PLAN FOR CERVICAL CANCER SCREENING

\begin{tabular}{|c|c|c|c|c|}
\hline \multirow{2}{*}{ Variable } & \multicolumn{2}{|c|}{ CRUDE OR $(95 \% \mathrm{CI})$} & \multicolumn{2}{|c|}{ Adjusted OR } \\
\hline & No plan & Undecided & No plan & Undecided \\
\hline \multicolumn{5}{|c|}{ LEVEL 1 (Socio-demographic) } \\
\hline Age & & & & \\
\hline (In years) & $0.97(0.91-1.04)$ & $1.02(0.98-1.06)$ & $0.95(0.86-1.05)$ & $1.06(1.00-1.13)$ \\
\hline Marital Status & \multicolumn{2}{|c|}{$\mathrm{p}=0.886$} & \multicolumn{2}{|c|}{$\mathrm{p}=0.859$} \\
\hline Single & 1 & 1 & 1 & 1 \\
\hline Married & $0.88(0.28-2.77)$ & $0.83(0.39-1.75)$ & $0.75(0.22-2.60)$ & $0.81(0.30-2.15)$ \\
\hline Ethnicity & \multicolumn{2}{|c|}{$\mathrm{p}=0.556$} & \multicolumn{2}{|c|}{$\mathrm{p}=0.680$} \\
\hline Yoruba & 1 & 1 & 1 & 1 \\
\hline Others & $0.80(0.32-1.96)$ & $0.73(0.40-1.32)$ & $0.82(0.29-2.35)$ & $1.28(0.64-2.57)$ \\
\hline Religion & \multicolumn{2}{|c|}{$\mathrm{p}=0.274$} & \multicolumn{2}{|c|}{$\mathrm{p}=0.259$} \\
\hline Christianity & 1 & 1 & 1 & 1 \\
\hline Islam & $1.78(0.84-3.75)$ & $0.95(0.58-1.57)$ & $2.08(0.85-5.10)$ & $1.26(0.67-2.27)$ \\
\hline Education & \multicolumn{2}{|c|}{$\mathrm{p}=0.050$} & \multicolumn{2}{|c|}{$\mathrm{p}=0.025$} \\
\hline Primary or none & 1 & 1 & 1 & 1 \\
\hline Secondary education & $0.83(0.23-2.99)$ & $3.68(1.22-11.08)$ & $1.10(0.28-4.32)$ & $6.01(1.68-21.55)$ \\
\hline Tertiary education & $0.62(0.21-1.84)$ & $1.83(0.65-5.12)$ & $0.90(0.23-3.55)$ & $3.05(0.82-11.28)$ \\
\hline Income & \multicolumn{2}{|c|}{$\mathrm{p}=0.031$} & \multicolumn{2}{|c|}{$\mathrm{p}=0.055$} \\
\hline Less than 50,000naira & 1 & 1 & 1 & 1 \\
\hline$\geq 50,000$ naira & $0.40(0.18-0.91)$ & $0.53(0.29-0.95)$ & $0.53(0.18-1.58)$ & $0.40(0.18-0.86)$ \\
\hline Parity & \multicolumn{2}{|c|}{$\mathrm{p}=0.049$} & \multicolumn{2}{|c|}{$\mathrm{p}=0.010$} \\
\hline Number of living children & $0.84(0.60-1.18)$ & $0.76(0.60-0.96)$ & $0.94(0.60-1.47)$ & $0.62(0.45-0.86)$ \\
\hline \multicolumn{5}{|c|}{ LEVEL 2 (Primary) } \\
\hline Awareness of HPV vaccination & \multicolumn{2}{|c|}{ p $<<0.001$} & \multicolumn{2}{|c|}{$\mathrm{p}=0.001$} \\
\hline No & 1 & 1 & 1 & 1 \\
\hline Yes & $0.34(0.16-0.72)$ & $0.24(0.14-0.40)$ & $0.37(0.13-1.03)$ & $0.24(0.11-0.53)$ \\
\hline Family history of HPV vaccination & \multicolumn{2}{|c|}{$\mathrm{p}<0.001$} & \multicolumn{2}{|c|}{$\mathrm{p}=0.002$} \\
\hline No & 1 & 1 & 1 & 1 \\
\hline Yes & $0.37(0.13-1.12)$ & $0.14(0.05-0.36)$ & $0.84(0.23-3.05)$ & $0.11(0.02-0.51)$ \\
\hline Concerns about HPV vaccination & \multicolumn{2}{|c|}{$\mathrm{p}=0.004$} & & \\
\hline No & 1 & 1 & 1 & 1 \\
\hline Yes & $0.39(0.16-0.93)$ & $0.38(0.21-0.71)$ & $0.49(0.18-1.36)$ & $0.50(0.23-1.11)$ \\
\hline $\begin{array}{c}\text { Awareness of HPV test and } \\
\text { screening }\end{array}$ & & & & \\
\hline No & 1 & 1 & 1 & 1 \\
\hline Yes & $0.23(0.10-0.53)$ & $0.29(0.17-0.50)$ & $0.41(0.14-1.19)$ & $0.87(0.40-1.93)$ \\
\hline & & L 3 (Secondary) & & \\
\hline Awareness of cervical cancer & & & & \\
\hline No & 1 & 1 & 1 & 1 \\
\hline Yes & $0.41(0.17-0.99)$ & $0.76(0.37-1.56)$ & $0.97(0.26-3.59)$ & $0.37(0.12-1.14)$ \\
\hline $\begin{array}{c}\text { Awareness of cervical cancer } \\
\text { prevention strategies }\end{array}$ & & & & \\
\hline No & 1 & 1 & 1 & 1 \\
\hline Yes & $0.71(0.25-2.07)$ & $0.46(0.22-0.97)$ & $1.64(0.44-6.02)$ & $2.01(0.70-5.76)$ \\
\hline Family history of pap smear test & & & & \\
\hline No & 1 & 1 & 1 & 1 \\
\hline Yes & $0.22(0.06-0.75)$ & $0.04(0.01-0.18)$ & $4.29(0.10-1.82)$ & $0.08(0.01-0.69)$ \\
\hline & & EL 4 (Distal) & & \\
\hline $\begin{array}{l}\text { Belief that cervical cancer is } \\
\text { associated with infection }\end{array}$ & & & & \\
\hline No & 1 & 1 & 1 & 1 \\
\hline Yes & $0.31(0.13-0.71)$ & $0.54(0.29-0.99)$ & $0.63(0.22-1.84)$ & $1.18(0.45-3.10)$ \\
\hline
\end{tabular}

Multinomial logistic regression analyses were performed to identify the key sociodemographic, primary, secondary and distal factors associated with saying no and being undecided about utilizing cervical cancer preventive measures. All predictors are adjusted for all other covariates in the model. Note: aOR adjusted odds ratios, $95 \%$ CIs $95 \%$ confidence intervals for the adjusted odds ratios are highlighted in bold. 


\section{DiscUSSION}

Findings from this study show a lack of knowledge and awareness about Human papillomavirus vaccination and cervical cancer screening among respondents. The intention to utilize prevention strategies was also low, with a good number of them stating that their most significant concern about screening was persistent pelvic pain. Distance to the facility was the most significant barrier to utilizing preventive services.

This study shows that the most significant proportion of the respondents were multiparous, which indicates that the women could have been exposed to human papillomavirus throughout their lives and hence the need to point the use of preventive services their way. Another factor contributing to the high prevalence of cervical cancer in the developing world compared to the developed world was the lack of awareness of cervical cancer [20], which supports findings from this study. The lack of knowledge and awareness noted in this study is alarming, as knowledge and awareness are significant determinants of the adoption of preventive services and may contribute to the low uptake of preventive services discovered in this study.

Results from the study also show that the most mentioned barrier to non-utilization of preventive services was the distance to a health facility, followed by the cost of screening, husband's permission, and un-exposure to causative factors. Despite being preventable by appropriate screening strategies, significant underutilization of cervical cancer screening services was reported in the study. The utilization of cervical cancer screening services depends on healthcareassociated factors, the availability of trained professionals, and women themselves. The significant barriers for non-use, identified by the women in the study of [21]-[23], were lack of awareness about the screening, illiteracy; some people think such services are for educated people. Also, when people are healthy, they do not bother about preventive services as they have other contending problems. It is generally not essential, and many have nonchalant attitudes to their health. Financial constraint was another problem as the available services were not free. The poverty level in our society is relatively high. Also, lack of symptoms and low perception of risk have been found among more educated women in Nigeria as primary reasons for not having cervical cancer screening tests. These findings corroborate findings from this study. Other findings supporting this study are [24], [25], where time, economic barriers, poor knowledge, underlying health and cultural beliefs, attitudes, language, and unhelpful attitudes of health professionals were identified as significant barriers to utilization of screening programs. Similarly, some authors identified that $30.4 \%$ of the respondents had not undergone cervical cancer screening because of fear of the screening procedure [26], which also significantly affected screening in this study. The findings from the study of [27] show that curative services were more prioritized over preventive services when the planning and allocation of resources from the national to the district level, which also affects utilization of preventive services even though not recognized in this study.

The results of the adjusted multinomial regression of plan for cervical cancer vaccination show that awareness of HPV vaccination significantly increased the odds of not planning to get the HPV vaccination. In contrast, awareness of cervical cancer prevention strategies significantly reduced the odds of not planning for HPV vaccination. These findings align with findings from other studies observing that people's level of awareness and knowledge appears to influence their intention or plan significantly to vaccinate [28]-[33]. Also, women who had a family history of pap smear tests were more likely to be indecisive about their plan.

In addition, the results of the adjusted multinomial regression of plan for cervical cancer screening among respondents show that women who had primary or no formal education have a higher odd of being undecided in their plan for cervical cancer screening. These findings are similar to that of [34]-[36], where it was found that illiterate women may have less intention to seek cervical screening. Illiterate women may have poor access to health services and experience a lower quality of life, which may delay seeking health care, even when symptoms of the disease are apparent, compared to better-educated women, who may respond faster. In contrast, women who earned 50,000 naira and above had a lower odd of being undecided in their plan for cervical cancer screening. Findings from this study are in consonance with findings from the study of [37], [38], where it was reported that increased socioeconomic status would place the women population in a better position economically and knowledge-wise. Thus, the likelihood of them planning and seeking cervical screening is improved. Cost might discourage some women from utilizing the screening, and as the number of living children increases, the odds of being undecided about cervical cancer screening tests drop. The odds of being undecided about cervical cancer screening were lower among women who were aware of HPV vaccination, those that had a family history of HPV vaccination, and those that reported a family history of the pap smear test.

The strength of this study is that it is a unique work carried out among a population of women who are not usually explicitly considered for the topic. The sample size for this study was a limitation, as it was small and may not have been representative enough to increase the power of the study. The industrial action of the resident doctors also affected women's attendance at antenatal clinics and hence caused a lower reach of the participants. More so, participants in this study (pregnant women) were mainly out of the recommended age for HPV vaccination (9-26 years old). Thus, their intention to vaccinate themselves could be low compared to their intention to vaccinate their future daughters. This study only focused on women of pregnancy age; thus, our result may not be representative of the entire population of women.

\section{CONCLUSION}

Cervical cancer preventive measures are more straightforward ways by which the menace of cervical cancer can be eliminated in our society. It involves the process of vaccination, which should be encouraged at younger ages and for young girls and boys, and screening for precancerous lesions, which should be promoted among pregnant women who are an established set of sexually active women to detect cases earlier and treat accordingly. Since cervical cancer is the only preventable cancer among women, awareness of the 
need to have the vaccination or be screened or utilize secondary preventive measures such as Pap smear must be promulgated. The findings of this study call for public health policy to implement a step-by-step strategy for cervical cancer prevention.

\section{ACKNOWLEDGMENT}

The authors wish to acknowledge Nurse Temitope Oladokun and Nurse Tobi Kadejo, who assisted in data collection. Also, the pregnant women who responded who responded to the questionnaires and participated in the key informant interviews

\section{FUNDING}

The authors appreciate the generous funding of the initial write-up, data collection, and data analysis by the African Union.

\section{CONFLICT OF INTEREST}

Authors declare that they do not have any conflict of interest.

\section{REFERENCES}

[1] WHO. World Cancer Report. [Internet] 2014 [cited 2015 November 6] Available from: http:/www.who.int/mediacentre/ factsheets/fs099/en/

[2] WHO. World Health Organization: Human papillomavirus vaccines. [Internet] 2017 [cited 2018 July 11] Available from: http://www.apps.who.int/iris/bitstream/handle/10665/255353/WER 9219.pdf? sequence $=1$.

[3] GLOBOCAN. Global Cancer Incidence, Mortality and Prevalence Fact sheets on Cervical Cancer. [Internet] 2020 Available from: https://gco.iarc.fr/today/fact-sheets-cancers

[4] WHO. World Health Organization. WHO guidelines for screening and treatment of precancerous lesions for cervical cancer prevention. 2013

[5] Centers for Disease Control and Prevention (CDC). Human Papillomavirus (HPV) Vaccination: What Everyone Should Know. [Internet] 2017 [cited 2017 October 17] Available from: https://www.cdc.gov/vaccines/vpd/hpv/public/index.html.

[6] WHO. World Health Organization: Human Papilloma Virus (HPV) and Cervical Cancer. [Internet] 2020 Available from: https://www.who.int/news-room/fact-sheets/detail/humanpapillomavirus-(hpv)-and-cervical-cancer.

[7] UNFPA. African Women's Development Fund, Integrated Africa cancer factsheet Focusing on cervical cancer, girls and women health, $H I V$ and maternal health. [Internet] 2014 Available from: https://www.who.int/pmnch/media/events/2014/africa_cancer_factshe et.pdf

[8] FMOH. Federal Ministry of Health. National strategic action plan (NSAP) for prevention and control of non-communicable diseases in Ethiopia 2014-2016. [Internet] 2014 Available from: https://www.iccp portal.org/system/files/plans/ETH_B3_National\%20Strategic\%20Acti on $\% 20$ Plan $\% 20 \% 28$ NSAP $\% 29 \% 20$ for $\% 20$ Prevention $\% 20$ and $\% 20 \mathrm{Co}$ ntrol\%20of\%20Non-Communicable\%20Diseases\%20-\%20Final.pdf

[9] FMOH. Federal Ministry of Health, Nigeria (FMOH). Nigeria National cancer control plan 2018 -2022. [Internet] 2018 Available from: https://www.iccpportal.org/system/files/plans/NCCP_Final\%20\%5B1 $\% 5$ D.pdf

[10] Jacobs IA, Chang CK, Salti GI. Coexistence of pregnancy and cancer. The American Surgeon. 2004; 70(11): 1025.

[11] Traen K, Svane D, Kryger-Baggesen N, Bertelsen K, Mogensen O. Stage Ib cervical cancer during pregnancy: planned delay in treatment-case report. European Journal of Gynaecological Oncology. 2006; 27(6): 615-7.

[12] Kaur H, Schmidt-Grimminger D, Remmenga SW, Chen B, Islam KM. Does human papillomavirus affect pregnancy outcomes? An analysis of hospital data 2012-2014. Int J Women's Health Wellness. 2015; 1.
[13] Nwankwo KC, Aniebue UU, Aguwa EN, Anarado AN, Agunwah E. Knowledge attitudes and practices of cervical cancer screening among urban and rural Nigerian women: a call for education and mass screening. European Journal of Cancer Care. 2011; 20(3): 362-7.

[14] Saslow D, Solomon D, Lawson HW, Killackey M, Kulasingam SL, Cain J, et al. American Cancer Society, American Society for Colposcopy and Cervical Pathology, and American Society for Clinical Pathology screening guidelines for the prevention and early detection of cervical cancer. CA: A Cancer Journal for Clinicians. 2012; 62(3): 147-72.

[15] Watts L, Joseph N, Velazquez A, Gonzalez M, Munro E, Muzikansky A, et al. Understanding barriers to cervical cancer screening among Hispanic women. American Journal of Obstetrics and Gynecology. 2009; 201(2): 199 e1-199 e8.

[16] Gebru Z, Gerbaba M, Dirar A. Utilization of cervical carcinoma screening service and associated factors among currently married women in Arba Minch town, southern Ethiopia. J Women's Health Care. 2016; 5(297): 2167-0420.

[17] Gregg JL. An unanticipated source of hope: stigma and cervical cancer in Brazil. Medical Anthropology Quarterly. 2011; 25(1): 70-84.

[18] Paz-Soldán VA, Bayer AM, Nussbaum L, Cabrera L. Structural barriers to screening for and treatment of cervical cancer in Peru. Reproductive Health Matters. 2012; 20(40): 49-58.

[19] Chidyaonga-Maseko F, Chirwa ML, Muula AS. Underutilization of cervical cancer prevention services in low-and-middle-income countries: a review of contributing factors. Pan African Medical Journal. 2015; 21(1).

[20] Feyi-Waboso PA, Kamanu C, Aluka C. Awareness and risk factors for cervical cancer among women in Aba, south-eastern Nigeria. Tropical Journal of Obstetrics and Gynaecology. 2005; 22: 25-6.

[21] Ndikom CM, Ofi BA. Awareness, perception, and factors affecting utilization of cervical cancer screening services among women in Ibadan, Nigeria: a qualitative study. Reproductive Health. 2012; 9(1): $1-8$.

[22] Udigwe GO. Knowledge, attitude, and practice of cervical cancer screening (pap smear) among female nurses in Nnewi South Eastern Nigeria. Nigerian Journal of Clinical Practice. 2006; 9(1): 40-3.

[23] Gharoro EP, Ikeanyi EN. An appraisal of the level of awareness and utilization of the Pap smear as a cervical cancer screening test among female health workers in a tertiary health institution. International Journal of Gynecologic Cancer. 2006; 16(3).

[24] Nygård JF, Nygård M, Skare GB, Thoresen SO. Pap smear screening in women under 30 in the Norwegian Coordinated Cervical Cancer Screening Program, with a comparison of immediate biopsy vs Pap smear triage of moderate dysplasia. Acta Cytologica. 2006; 50(3): 295302.

[25] Thomas VN, Saleem T, Abraham R. Barriers to effective uptake of cancer screening among Black and minority ethnic groups. International journal of palliative nursing. 2005; 11(11): 562-71.

[26] Pegu B, Dhiman N, Chaturvedi J, Sharma SK. Nurse's knowledge and attitude regarding cervical cancer screening at a tertiary care hospital. Int J Reprod Contracept Obstet Gynecol. 2017; 6: 907-10.

[27] Mugassa AM, Frumence G. Factors influencing the uptake of cervical cancer screening services in Tanzania: A health system perspective from national and district levels. Nursing Open. 2020; 7(1): 345-54.

[28] Donadiki EM, Jiménez-García R, Hernández-Barrera V, CarrascoGarrido P, Lopez de Andres A, Jimenez-Trujillo I, et al. Knowledge of the HPV vaccine and its association with vaccine uptake among female higher-education students in Greece. Human Vaccines \& Immunotherapeutics. 2013; 9(2): 300-5.

[29] Jelastopulu E, Fafliora E, Plota A, Babalis V, Bartsokas C, Poulas K, et al. Knowledge, behaviours and attitudes regarding HPV infection and its prevention in female students in West Greece. Age. 2016; 21:206.

[30] Chiang VC, Wong HT, Yeung PC, Choi YK, Fok MS, Mak OI, et al. Attitude, acceptability and knowledge of HPV vaccination among local university students in Hong Kong. International Journal of Environmental Research and Public Health. 2016; 13(5): 486.

[31] Bendik MK, Mayo RM, Parker VG. Knowledge, perceptions, and motivations related to HPV vaccination among college women. Journal of Cancer Education. 2011; 26(3): 459-64.

[32] Feng S, Xu X, Jin Y, Yao X. Women's knowledge of human papillomavirus (HPV) and their attitudes toward HPV vaccine: Preparing for HPV vaccination in China. Asia Pacific Journal of Public Health. 2012.

[33] Fernandez ME, Le YC, Fernandez-Espada N, Calo, WA, Savas LS, Velez C, et al. Knowledge, attitudes, and beliefs about human papillomavirus (HPV) vaccination among Puerto Rican mothers and daughters, 2010: A qualitative study. Prev. Chronic Dis. 2014; 11: E212. 
[34] Gerald EI, Ogwuche CH. Educational level, sex and church affiliation on health seeking behaviour among parishioners in Makurdi metropolis of Benue state. Journal of Educational Policy and Entrepreneurial Research. 2014; 1(2): 311-6.

[35] Lee M, Park EC, Chang HS, Kwon JA, Yoo KB, Kim TH. Socioeconomic disparity in cervical cancer screening among Korean women: 1998-2010. BMC Public Health. 2013; 13(1): 1-8.

[36] Lyimo FS, Beran TN. Demographic, knowledge, attitudinal, and accessibility factors associated with uptake of cervical cancer screening among women in a rural district of Tanzania: three public policy implications. BMC Public Health. 2012; 12(1): 22.

[37] Nene B, Jayant K, Arrossi S, Shastri S, Budukh A, Hingmire S, et al. Determinants of women's participation in cervical cancer screening trial, Maharashtra, India. Bulletin of the World Health Organization. 2007; 85: 264-72.

[38] Gichangi, P., Estambale, B., Bwayo, J., 2003. Knowledge and practice about cervical cancer and Pap smear among patients at Kenyatta National Hospital, Nairobi. Int J Gynecol Canc. 13: 827-833. 